\title{
Climate change mitigation strategies for mechanically controlled repositories: The case of The National Archives, Kew
}

Sung, Hong; Strlic, Matija; Ridley, Ian; Ntanos, Konstantinos; Bell, Nancy; Cassar, May

https://researchrepository.rmit.edu.au/esploro/outputs/9921858390701341/filesAndLinks?institution=61RMIT_INST\&index=null

Sung, H., Strlic, M., Ridley, I., Ntanos, K., Bell, N., \& Cassar, M. (2012). Climate change mitigation strategies for mechanically controlled repositories: The case of The National Archives, Kew. Atmospheric Environment, 49, 163-170. https://doi.org/10.1016/j.atmosenv.2011.12.003

Document Version: Accepted Manuscript

Published Version: https://doi.org/10.1016/j.atmosenv.2011.12.003

Repository homepage: https://researchrepository.rmit.edu.au (C) 2011 Elsevier Ltd

Downloaded On 2023/04/26 20:41:57 +1000 
Thank you for downloading this document from the RMIT Research Repository.

The RMIT Research Repository is an open access database showcasing the research outputs of RMIT University researchers.

RMIT Research Repository: http://researchbank.rmit.edu.au/

\section{Citation:}

Sung, H, Strlic, M, Ridley, I, Ntanos, K, Bell, N and Cassar, M 2012, 'Climate change mitigation strategies for mechanically controlled repositories: The case of The National Archives, Kew', Atmospheric Environment, vol. 49, pp. 163-170.

See this record in the RMIT Research Repository at:

http://researchbank.rmit.edu.au/view/rmit:16406

Version: Accepted Manuscript

Copyright Statement: (c) 2011 Elsevier Ltd

Link to Published Version:

http://dx.doi.org/10.1016/j.atmosenv.2011.12.003 


\section{Climate change mitigation strategies for mechanically controlled repositories:}

\section{the case of The National Archives, Kew}

Sung H. Hong ${ }^{1}$, Matija Strlič ${ }^{1}$, lan Ridley ${ }^{1}$, Konstantinos Ntanos ${ }^{2}$, Nancy Bell ${ }^{2}$, May Cassar ${ }^{1}$

${ }^{1}$ The Bartlett School of Graduate Studies, Centre for Sustainable Heritage, University College London,

Central House, 14 Upper Woburn Street, London WC1H ONN, United Kingdom

${ }^{2}$ The National Archives, Kew, Richmond, Surrey, TW9 4DU, United Kingdom

Address for correspondence

Matija Strlič

The Bartlett School of Graduate Studies, Centre for Sustainable Heritage, University College London, Central House, 14 Upper Woburn Street, London WC1H ONN, United Kingdom

Tel: +44 (0) 2031089036

E-mail: m.strlic@ucl.ac.uk 


\section{Abstract}

A computer based building simulation model is developed to examine the energy load and environmental management in The National Archives Q1 repository building in Kew, UK to optimise environmental management and examine the impacts of climate change. The need to accurately simulate the hygrothermal environment inside the archive building which houses mainly paper-based records led to the choice of EnergyPlus as the modelling software. The study presents the simulation results of five environmental strategies which predict energy saving potential as high as $43 \%$ without significantly affecting the quality of the preservation environment. The effect of climate change is predicted to have little impact on the archive environment due to the filtering effect of the air conditioning system. On the other hand, an increase in total energy load by $15 \%$ and $24 \%$ is predicted under the worst case climate change scenario in 2050 and 2080 respectively if the current environmental management practice is continued into the future. However, the identified energy saving strategies could represent possible mitigative solutions in reducing future energy load against the impact of climate change.

\section{Keywords}

Heritage collection, archival repositories, climate change, modelling, energy consumption 


\section{Introduction}

Archive buildings normally operate under strict environmental guidelines to ensure long-term preservation of collections. In the UK, the recommended environmental conditions for the storage of archival documents are between $16{ }^{\circ} \mathrm{C}$ and $19{ }^{\circ} \mathrm{C}$ and between $45 \%$ and $60 \%$ relative humidity (RH) [BS5454, 2000; Thomson, 1978], strict parameters which can only be provided by mechanical air conditioning [Padfield, et al, 2007]. The advantages of mechanical air conditioning are close control of the internal environment while effectively filtering out the external conditions [Hacker et al, 2005]. On the other hand the disadvantages are high financial and environmental costs associated with its operation.

With increasing fuel cost and awareness of global warming, there is a growing need for heritage organizations to re-assess their environmental management strategies to reduce energy cost and greenhouse gas emissions [Directive 2010/31/EU]. However, implementing energy saving environmental strategies in an archive building poses a significant challenge in that unless these are undertaken with a comprehensive understanding of their impact on the preservation environment, they risk accelerated degradation of archived collection.

Fortunately, the availability of computer based engineering models provides the opportunity to preassess the effect of energy saving strategies on the archive environment. However, the modelling of an archive poses a unique challenge of its own in that the presence of hygroscopic internal mass [Svennberg et al, 2007], which is mainly paper-based, creates a complex hygrothermal environment which the model must take into account for accurate simulations [Plathner et al, 1998; Hong et al, 2003; Rose et al, 2008].

This study examines the case of the Q1 repository at The National Archives (TNA) in Kew, UK. The computer based building energy and environment simulation model EnergyPlus was used to test the efficacy of different building environment management strategies in reducing the energy load while 
providing a stable archival preservation environment. The potential of these energy saving strategies as means to mitigate the effect of future climate change is also examined.

\section{Materials and Methods}

TNA is the official archive for England, Wales and the central UK government containing 900 years of historical records. TNA currently holds and provides public access to more than 10 million parchment and paper-based records that occupy $180 \mathrm{~km}$ of shelving.

The case study archive is located in the Q1 building which was constructed in 1975 to provide archival storage space of approximately $22,000 \mathrm{~m}^{2}$ in floor area divided into three separate floors. The building is of reinforced concrete structure clad in precast concrete with deeply recessed and non-operable strip windows. The walls and roof have $50 \mathrm{~mm}$ and $120 \mathrm{~mm}$ insulation respectively and the windows are double glazed. Most of the archival collection is paper-based and is stored in purpose-made record boxes held in open shelves (Fig. 1).

The storage environment is mechanically conditioned continuously throughout the year by four separate heating, ventilating, and air conditioning (HVAC) units operated to maintain the storage environment temperature to $18{ }^{\circ} \mathrm{C} \pm 1{ }^{\circ} \mathrm{C}$ and $\mathrm{RH}$ to $50 \% \pm 5 \%$. The conditioned air is supplied at a rate of $15 \mathrm{~m}^{3} / \mathrm{sec}$ through a system of exposed ductwork installed along the repository periphery and then extracted from the building core at a rate of $5 \mathrm{~m}^{3} / \mathrm{sec}$. The imbalance in air supply and return rates creates a pressurised internal environment resulting in negligible air ingress from the exterior by infiltration. The external air instead enters the building through the HVAC system $10 \%$ of whose supply air is replenished with fresh air.

\subsection{Environment Monitoring}

Temperature and $\mathrm{RH}$ of the archive have been recorded at 15-min intervals at 129 different locations since the beginning of 2008 using Hanwell ml4106 Radiotelemetry Temp/RH Transmitters (accuracy: $+/-0.2{ }^{\circ} \mathrm{C},+/-2 \%$, Hanwell Instruments) [Ntanos et al, 2007]. From June to November 2009 the supply 
temperature and $\mathrm{RH}$ of the conditioned air have also been monitored at half hourly interval by attaching HOBO U12-011 Temp/RH Loggers (accuracy: $+/-0.35^{\circ} \mathrm{C},+/-2.5 \%$, Tempcon Instrumentation) to the HVAC air supply grilles (8 air supply grilles per floor).

The results of the environmental monitoring in 2009 showed that the mean annual temperature in the archive was $19.0 \pm 0.4{ }^{\circ} \mathrm{C}$ and $\mathrm{RH} 49.1 \% \pm 1.8 \%$ providing storage conditions close to the target levels of $18 \pm 1^{\circ} \mathrm{C}$ and $50 \pm 5 \%$. Differences were observed between the floors with $2^{\text {nd }}$ floor mean annual temperature of $19.3 \pm 0.4{ }^{\circ} \mathrm{C}$ and $\mathrm{RH} 48.8 \pm 4.4 \% ; 3^{\text {rd }}$ floor, $18.6 \pm 0.5^{\circ} \mathrm{C}, 50.2 \pm 5.2 \%$ and $4^{\text {th }}$ floor $19.1 \pm 0.7^{\circ} \mathrm{C}, 48.3 \pm 5.8 \%$. Greater differences were observed within each floor with peripheral areas exhibiting about $1.5^{\circ} \mathrm{C}$ lower temperatures and $5 \%$ higher $\mathrm{RH}$ when compared to the central areas. Variations were also found in the monthly averages with June recording the lowest mean temperature of $18.2 \pm 0.3^{\circ} \mathrm{C}$ and December the highest of $19.6 \pm 0.4{ }^{\circ} \mathrm{C}$ while July recorded the highest mean RH of $55.4 \pm 2.0 \%$ and January the lowest $41.2 \pm 2.0 \%$.

The monitoring of temperature and RH of the HVAC supply air proved to be important in understanding how the actual HVAC system performed. All four HVAC units were found to operate under different set point schedules while differences were found between the floors of each quadrant despite each quadrant being serviced by the same HVAC unit. In general, the supply condition was found to be very unsteady frequently showing temperature swings as high as $6{ }^{\circ} \mathrm{C}$ and RH swings of $20 \%$ within a 12 hour period.

\subsection{Modelling Challenge}

Since paper has hygroscopic properties it will release water in dry environments and absorb water in humid environments [Derluyn, 2007]. The presence of a vast amount of paper in a room such as in an archive will therefore modify the storage environment through a complex process of moisture absorption, storage and release affecting the indoor humidity performance by moderating changes in $\mathrm{RH}$. Accordingly an energy and environment modelling software that is used to model an archive must take into account this dynamic hygrothermal interaction between the room and the stored 
content for accurate simulation. In this study the building energy and environment simulation software EnergyPlus was selected as the suitable modelling tool for its advanced Heat and Moisture Transfer (HAMT) algorithm which is designed to simulate the movement and storage of heat and moisture to and from the environment and the surrounding physical elements [EnergyPlus; Künzel, 1995].

An integral part of the HAMT algorithm is the specification of material isothermal property which determines the heat storage capacity of physical elements as a function of moisture content. For a greater modelling accuracy, the isothermal property (moisture absorption) of the collection (density: $500 \mathrm{~kg} / \mathrm{m}^{3}$; specific heat capacity: $1.3 \mathrm{~kJ} / \mathrm{kgK}$ [Engineering Toolbox]) was measured in a climate chamber by testing a typical record box containing mock-up manuscript as a snapshot of the hygroscopic property of the archive. The sorption isotherm of the mock-up measured at $18{ }^{\circ} \mathrm{C}$ is shown in Fig. 3.

\subsection{Modelling Process}

Fig. 2 illustrates the process involved from model development to scenario testing. The process can be categorized into four different phases of model construction, model calibration, modelling baseline and modelling scenarios.

Model construction involved constructing a proof of concept model based on the building physical characteristic which included dimension, internal layout and material property (including monitored sorption isotherm) [Kumaran, 1996]. The sources of internal heat gain were specified from occupants, equipment and lighting although their impact is assumed to be very small in the case study archive. An idealized HVAC system was introduced with an air supply rate of $15 \mathrm{~m}^{3} / \mathrm{s}$ and fresh air intake of $10 \%$. Although the HVAC model required the specification of mechanical components such as fans, dehumidifiers, fresh air inlet etc., these were not intended to re-create the actual HVAC system but only to achieve a functioning HVAC model. 
The model was constructed separately for the $2^{\text {nd }}, 3^{\text {rd }}$ and the $4^{\text {th }}$ floors of the Q1 building in order to keep the time needed per simulation reasonable. All internal ceilings and floors were modelled as adiabatic surfaces, i.e. next to zones with the same thermal conditions hence not having to account for any heat exchange between the floors. This is considered to be a reasonable assumption since the three floors have shown little difference in their mean temperatures.

Although the actual floors are open in plan, the modelled floors were sub-divided into different thermal zones ( $2^{\text {nd }}$ floor: 16 zones, $3^{\text {rd }}$ floor: 23 zones, $4^{\text {th }}$ floor: 23 zones) to account for different micro-climates. The zones were determined based on internal wall layout, proximity to external wall and environmental monitoring grid established by TNA.

Model calibration was performed in two stages. First the HVAC performance was calibrated by specifying the actual monitored temperature and RH of the HVAC supply air as the hourly HVAC thermostat and humidistat settings, a critical step considering the varied performance exhibited by each HVAC unit and the large temperature and RH swings characteristic of the conditioned air.

The second step in model calibration involved matching the simulated environmental performance to the monitored temperature and $\mathrm{RH}$ of each zone in the archive until a satisfactory agreement was achieved. Despite the availability of 18 months of monitored environmental data, the calibration was performed against 6 months of data to match with the available monitored HVAC data. Calibration was performed mainly by adjusting the modelled HVAC supply fan pressure and zone-to-zone air change rate. Although parameter such as zone-to-zone air change rate is typically determined from other computer based studies such as a computational fluid dynamic (CFD) anaysis, this was not performed in this study due to time constraint. Instead, the modelled airflow assumed principle air movement from the building perimeter to the centre as the repository building is currently designed to do, and the zone-to-zone air change rate was estimated until a good agreement was achieved between the monitored and the modelled environmental performance in each zone. This method 
proved to give realistic results with an average zone-to-zone air velocity of $20 \mathrm{~mm} / \mathrm{sec}$ near the building periphery increasing to $100 \mathrm{~mm} / \mathrm{sec}$ near the centre reflecting increased air volume.

The root mean square difference between the modelled and the monitored temperature and $\mathrm{RH}$ has shown the model to be accurate in simulating the mean monthly internal temperature to within 0.5 ${ }^{\circ} \mathrm{C}$ (minimum hourly discrepancy: $0.1{ }^{\circ} \mathrm{C}$, maximum hourly discrepancy: $1.5^{\circ} \mathrm{C}$ ) and the mean monthly RH to within $2.1 \%$ (minimum hourly discrepancy: $0.8 \%$, maximum hourly discrepancy: $6.0 \%$ ), which are within measurement uncertainty of the environmental monitoring data loggers.

Finally, modelling baseline involved establishing a reference energy and environmental performance of the archive over a typical year under the current environmental management practice. In building the baseline model, the HVAC supply condition monitored in autumn was assumed for spring due to the unavailability of monitored data for this period. The baseline model forms the reference against which the impact of various what-if environmental scenarios are compared and quantified. The archive performance in year 2009 was used as the baseline.

The last stage of modelling involved testing various environmental management scenarios using the prototype model to examine their impact on the environmental and energy performance. All scenarios were tested under three different climate conditions of 2009, 2050 and 2080 to examine the impact of climate change on the archive performance. Various scenarios were tested of which the results of the following are presented.

1. Baseline: Monitored performance.

2. Scenario: Increased roof insulation.

3. Scenario: Changing repository load.

4. Scenario: Weekend HVAC power down.

5. Scenario: Night time HVAC power down. 
6. Scenario: Seasonal adjustment of HVAC set points.

\subsection{Modelled Data}

The model is designed to produce a range of output variables which include monthly heating and cooling energy loads and hourly predictions in indoor temperature and $\mathrm{RH}$. The suitability of various scenarios in providing an adequate conservation environment was evaluated by determining the isoperm.

The isoperm combines the effect of temperature $(T)$ and RH into a single index which compares the permanence of paper-based collections at any combination of $\mathrm{T}$ and $\mathrm{RH}$ relatively to the permanence at $20^{\circ} \mathrm{C}$ and $50 \% \mathrm{RH}$, typically accepted as 'normal' environmental conditions for the preservation of a paper-based collection and are assigned the isoperm index of 1 . TNA repository aims to maintain an isoperm level of 1.33 by providing an archival condition of $18^{\circ} \mathrm{C}$ and $50 \% \mathrm{RH}$. The isoperm is determined based on the equation as proposed by Sebera [1994] taking into account the activation energy of $35 \mathrm{kcal} / \mathrm{mol}$. Isoperms should not be used without caution, as it is well known that the calculations are not valid for very dry or very humid environments. Additionally, isoperms underestimate the effect of $\mathrm{RH}$, as they assume that the rate of degradation increases with $\mathrm{RH}$ linearly, while it in fact increases exponentially [Strlič et al, 2005]. However, as currently no more accurate calculation of isoperms is available, the above equation was used. The average monthly isoperm values are determined in this study using hourly temperature and $\mathrm{RH}$ data.

\subsection{Climate Change Scenarios}

The UK Climate Projections (UKCP09) provides $21^{\text {st }}$ century UK climate scenarios for studies on climate change impacts and vulnerability and adaptation [UKCP09]. The climate scenarios in UKCP09 introduces probabilistic projections that take into account the differences in an ensemble of 12 different international global climate change models plus the Met Hadley Centre global model. The projection is therefore designed to accurately reflect the complexity and uncertainty behind the current state of science in predicting the effect of climate change. 
The repository performance under the climate change scenario was investigated using the most conservative approach $\left(90^{\text {th }}\right.$ percentile) under the worst case scenarios for the years 2050 and 2080 based on the UKCP09 projections. The future weather files for London based on the UKCP09 projections were available from University of Exeter in Chartered Institue of Building Services Engineers (CIBSE) weather format. [Eames, 2011, Prometheus, 2010]. Fig. 4 compares the hourly temperature distribution of London in 2009 to the 2050 and 2080 projections. The mean external temperatures are predicted to increase by $2.8^{\circ} \mathrm{C}$ in 2050 and by $5.1{ }^{\circ} \mathrm{C}$ in 2080 under the future scenarios assumed in this study.

\subsection{Energy Load}

All energy discussions in this report specifically refer to energy load normalized per floor area $\left(\mathrm{kWh} / \mathrm{m}^{2}\right)$. Energy load quantifies the sensible heat supplied or removed (by providing "coolth") by the HVAC system. By focusing on the energy load, the HVAC system is treated as a black box, i.e. an idealized system introduced only to provide conditioned air into the modelled archive, with energy load quantifying the box's output. No attempt was made to recreate the actual HVAC system in the model due to the unavailability of sub-metered enegy consumption data from the HVAC operation to which the modelled energy performance can be compared.

EnergyPlus calculates the energy load by multiplying the supply air mass flow rate by the difference between the supply air temperature and the room air temperature. The room air temperature is a function of heat transfer across the building fabric based on transient modelling using hourly weather data and passive heat gains from occupants, equipment and lighting and the impact of latent energy from moisture interaction (evaporation enthalpy of water 2,489 J/g) [EnergyPlus] between the room environment and the surrounding physical fabric most notably the archive in this particular case study. 


\section{Results}

\subsection{Baseline: Monitored Performance}

The environmental management scenario of 2009 forms the reference baseline condition. The mean monthly isoperm in Fig. 5 shows that the quality of the preservation environment in 2009 was satisfactory with the mean annual isoperm indices of all three repository floors in the range of 1.2 to 1.3. The future climate is predicted to have very little impact on the environmental performance of the archive since the external elements are filtered out by the HVAC system resulting in no significant impact on the quality of the preservation environment. As a result only the 2009 baseline performance is shown in Fig. 5.

Table 1 shows the annual baseline energy load of the repository disaggregated into heating and cooling loads with the latter constituting almost $70 \%$ of the total load. If the current environmental management strategy is maintained into 2050 and 2080, the total energy load is predicted to increase by $15 \%$ and $24 \%$ respectively as a result of a greater increase in the cooling load offsetting any saving in the heating load. The proportion taken up by the cooling load is also expected to increase to $81 \%$ in 2050 and $86 \%$ in 2080.

\subsection{Scenario: Increased Roof Insulation}

The roof insulation thickness is varied from $0 \mathrm{~mm}$ to $1200 \mathrm{~mm}$ and its impact on the energy load and the environmental performance of the $4^{\text {th }}$ floor repository is examined. The roof insulation thickness of $120 \mathrm{~mm}$ represents the baseline condition.

Changing the roof insulation thickness resulted in little impact on the environmental performance of the repository, as measured in terms of mean monthly isoperm, in relation to the basline condition. Similarly, little impact was observed on the total energy load as shown in Fig. 6 from the baseline. The lack of change in the total energy load is explained when it is disaggregated into heating and cooling loads, where the saving in the heating load with increasing insulation level is found to be offset by an increase in the cooling load. 
On the other hand, increasing the insulation level is predicted to be beneficial with $7 \%$ and $10 \%$ savings expected in 2050 and 2080 respectively when compared to the future load performance under the baseline scenario.

\subsection{Scenario: Changing Repository Load}

This scenario explores the impact of archive volume on the energy load and the environmental performance. The volume is quantified in percentage relative to the baseline: $0 \%$ (no archive), $50 \%$, $100 \%$ (baseline), $150 \%$ and $200 \%$.

The RH performance of the $3^{\text {rd }}$ floor repository in Fig. 7 (only June and July shown for clarity) shows that the presence of archive content in the repository has a stabilizing effect on the $\mathrm{RH}$ compared to that of an empty building (0\%). This is shown by the diminishing standard deviation in the mean annual RH from $5.7 \%$ of the empty building to $5.0 \%$ of the doubled archive volume (200\%). However, there is diminishing return on the stabilizing capacity from increasing archive content with a $0.5 \%$ lower standard deviation in the baseline case (100\%) compared to that of the empty building while doubling the volume resulted in only a further $0.2 \%$ reduction from the baseline case. The overall effect of doubling the archive volume on temperature is also small with only a $0.1^{\circ} \mathrm{C}$ increase in the mean annual temperature (not shown) relative to the baseline. Despite stabilisation of RH performance, increased archival volume was found to have little impact on the mean monthly isoperm performance. No further analysis was undertaken to observe the impact on the short-term isoperm performance.

Fig. 8 shows that increasing the archive volume is associated with a small increase in the energy load. An empty repository is found to require $4 \%$ less energy compared to the baseline while doubling the archive volume is found to increase the energy load by $3 \%$. Reducing the archive volume is predicted to be beneficial in mitigating some of the increase in the future energy load. However, it is important to clarify that increase in the energy load may not neccessarily indicate an increase in the energy 
consumed by the HVAC system since reduced RH fluctuation from archival presence may reduce humidification/dehumidification demand on the system [Olalekan, 2006] .

\subsection{Scenario: Weekend HVAC Power Down}

This scenario explores the effect of weekend HVAC power down from 8 pm Saturday to 7 am Monday on the energy load and the environmental performance. Fig. 9 shows a slight reduction in the mean monthly isoperms under this scenario but still providing a satisfactory preservation environment.

A comparison of the energy load in Fig. 10 shows a 14\% reduction in the total energy load under this scenario as a result of reduction in both the heating and cooling loads. By extending the power down until Tuesday morning, a greater energy saving of $22 \%$ is observed (not shown). In 2050 and 2080, this scenario is predicted to reduce the energy by $10 \%$ and $9 \%$ respectively in relation to the future baseline load.

\subsection{Scenario: Night Time HVAC Power Down}

This scenario explores the effect of night time HVAC power down from $8 \mathrm{pm}$ until 7 am the following day on the energy load and the environmental performance. Fig. 11 shows a reduction in the mean monthly isoperms under this scenario with all three repository floors dropping below 1 in August.

A comparison of the energy load in Fig. 12 shows a 26\% reduction in the total energy load under this scenario. Although this scenario is predicted to be effective in reducing the future energy load, its impact is found to diminish to $19 \%$ in 2050 and to $17 \%$ in 2080 relative to the future baseline load.

\subsection{Scenario: Seasonal Adjustment of HVAC Set Points}

This scenario explores the effect of seasonal adjustment in the HVAC temperature and RH set points on the enegy load and the environmental performance. In this scenario the temperature set point is incremented each month from $16^{\circ} \mathrm{C}$ in February to $20^{\circ} \mathrm{C}$ in September and then back to $16^{\circ} \mathrm{C}$ by 
December. Similarly, the humidistat setting is incrementally raised from $35 \%$ in February to $55 \%$ by September and then back to $35 \%$ by December. The seasonal changes are aimed to reduce the loads associated with heating/cooling and humidificaiton/dehumidification. This scenario is notable in that the winter $\mathrm{RH}$ is brought below the recommended minimum $\mathrm{RH}$ level of $45 \%$.

Fig. 13 shows that although this strategy resulted in reduced mean monthly isoperm performance from May to September relative to the baseline, the decreased performance is made up with increased performance during the rest of the year with an overall improvement in the mean annual isoperm performance.

Fig. 14 shows that the scenario is also very effective in reducing the energy load from the present level by as much as $43 \%$. The effectivenss of this scenario in reducing the energy load is however expected to diminish into the future with savings of $29 \%$ in 2050 and $23 \%$ in 2080 relative to the future baseline load.

\section{Discussion and Conclusion}

The effects of different energy saving building environment management strategies and climate change on the environmental and energy performance in the Q1 repository at TNA was examined using a computer based building energy and environment simulation model.

Of the five environmental strategies presented in this study, the daily night time HVAC power down strategy (Section 3.5) was predicted to reduce the total energy load by $26 \%$ when compared to the current envionmental management strategy while powering down the HVAC over the weekend (Section 3.4 ) resulted in savings of $14 \%$ to $22 \%$ depending on whether the system was powered up on Monday or Tuesday morning respectively. The highest energy saving was observed with seasonal adjustment of the HVAC set point (Section 3.6) resulting in a saving as high as $43 \%$.

In addition to these savings, the quality of the archival preservation environment was also found to be satisfactory in all strategies with the mean annual isoperm values remaining above the index of 1 . 
In the case of the seasonally adjusted set point scenario (Section 3.6), the large energy saving was accompanied by a slight improvement in the quality of the presevation environment.

The archive environment was found to be robust against the effect of climate change. This is due to the reduced temporal relationship between the the external climate and the archive environment in an HVAC controlled building. On the other hand, the effect of climate change is reflected in the energy load which is predicted to increase by $15 \%$ in 2050 and $24 \%$ in 2080 mainly as a result of increased cooling load offseting any saving in the heating load if the current environmental management scheme is maintained into the future. The increase in the energy load can pose a potenal risk to the HVAC capacity in coping with increased cooling and dehumidification loads [Hacker et at, 2005]. These possibilities however were not examined in this study since detailed information on the HVAC capacity was unknown while it is assumed that many of the HVAC components are likely to be replaced into the future.

The environmental management strategies designed to reduce the current energy load were also found to be effective, albeit by a diminished degree, as mitigative strategies in reducing the future energy load against the impact of climate change. One notable scenario is increased roof insulation which on the one hand had little effect in reducing the total energy load under the present climate condition while on the other hand showed increased energy saving potential in the future.

However, across all strategies examined, climate change is predicted to increase the energy load demand indicating that delivering the archival condition according to the current environmental guidelines (temperature: $18{ }^{\circ} \mathrm{C} \pm 1{ }^{\circ} \mathrm{C}$; $\mathrm{RH}: 50 \% \pm 5 \%$ ) will most likely be achieved with increased financial cost into the future. The dominant cooling load characteristic of the case study building also means that it is particularly susceptible to increased external temperature. These issues are likely to be encountered in other HVAC controlled archives in temperate climates and may play a part in reexamination of archival preservation standards in light of climate change. As one scenario (section 3.6) showed, by laxing the environmental standard, a significant energy saving was predicted but 
without a detrimental impact on the quality of the preservation environment. Furthermore, the fluctuations observed in the conditioned air and the presence of micro-climatic differences in the archive seem to indicate realistic limitations in meeting the narrow environmental standard even in a mechanically controlled building.

The methodology followed in this study in building the energy and environment simulation model can similarly be applied to modelling of other archives including those that are non-mechanically conditioned. It is important to emphasize that the strength of the model in this study lay in the availability of detailed monitored temperature and RH of the archive and the HVAC conditioned air providing the necessary references against which the model performance was compared and calibrated. The lab measurement of the hygroscopic property of the archive content and its specification in the modelled material property was equally vital in increasing the hygrothermal simulation accuracy giving robustness to the modelled results. No attempt was made to measure the air infiltration rate in this study due to the building's operational nature. However for other archives, this variable is likely to be an important parameter, especially if the building is leaky or operate windows.

\section{Acknowledgement}

This study was undertaken with the support of The National Archives.

\section{References}

Derluyn, H., Janssen, H., Diepens, J., Derome, D., Carmeliet, J., 2007. Hygroscopic Behavior of Paper and Books, Journal of Building Physics 31(1), pp. 9-34.

Eames, M., Kershaw, T., Coley, D., 2011. On the creation of future probabilistic design weather years from UKCP09, Building Services Engineering Research and Technology 32(2), pp. 127-142. 
Hacker, J. N., Holmes, M. J., Belcher, S. B., Davies, G. D., 2005. CIBSE TM36: Climate change and the indoor environment: impacts and adaptation, The Chartered Institution of Building Services Engineers, London.

Hong, S. H., Ridley, I., Oreszczyn, T., 2003. A Hygrothermal Monitoring and Modeling of a Historic Roof, In: $8^{\text {th }}$ International IBPSA Conference, 11-14 August 2003, Eindhoven, Netherlands, pp. 515522.

Kumaran, M. K., 1996. Heat, Air and Moisture Transfer in Insulated Envelope Parts, Annex 24 Volume 3 Task 3: Material Properties, International Energy Agency, Energy Conservation in Buildings and Community Systems.

Künzel, H. M., 1995. Simultaneous heat and moisture transport in building components. One- and two-dimensional calculation using simple parameters, Fraunhofer IRB Verlag, Stuttgart.

Ntanos, K., Bell, N., 2007. A holistic appraisal of environmental conditions in The National Archives, UK. In: Museum microclimates: contributions to the Copenhagen conference, Copenhagen, Denmark, 19-23 November 2007.

Olalekan, F. O., Simonson, C. J., 2006. Moisture buffering capacity of hygroscopic building materials: Experimental facilities and energy impact, Energy and Buildings 38(10), pp. 1270-1282.

Padfield, T., Larsen, P. K., Jensen, L. A., Svendsen, M. R., 2007. The Potential and Limits for Passive Air Conditioning of Museums, Stores and Archives. In: Museum microclimates: contributions to the Copenhagen conference, Copenhagen, Denmark, 19-23 November 2007.

Plathner, P., Littler, J., Cripps, A., 1998. Modelling Water Vapour Conditions in Dwellings, Proceedings, $3^{\text {rd }}$ International Symposium on Humidity and Moisture, National Physical Laboratory, London, vol.2 pp. 64-72.

Rose, C., Grau, K., 2008. Moisture Buffering and its Consequence in Whole Building Hygrothermal Modeling, Journal of Building Physics 31(4), pp. 333-360. 
Sebera, D. K., 1994. Isoperms An Environmental Management Tool (http://cool.conservationus.org/byauth/sebera/isoperm/), accessed August 2010.

Svennberg, K., Lengsfeld, K., Harderup, L. E., Holm, A., 2007. Previous Experimental Studies and Field Measurements on Moisture Buffering by Indoor Surface Materials, Journal of Building Physics 30(3), pp. 261-274.

Thomson, G., 1978. The Museum Environment, $1^{\text {st }}$ edition, Butterworths, London.

Ageing and Stabilisation of Paper, in: M. Strlič, J. Kolar (Eds.), 2005. National and University Library,Ljubljana, Slovenia.

Directive 2010/31/EU of the European Parliament and of the Council of 19 May 2010 on the energy performance of buildings, 2010. Official Journal of the European Union.

EnergyPlus Engineering Reference, The Reference to EnergyPlus Calculations, 2009. The US Department of Energy.

EnergyPlus software package, version 3.1.0. The US Department of Energy.

http://www.eere.energy.gov/buildings/energyplus/

The Engineering ToolBox. http://www.engineeringtoolbox.com/specific-heat-solids-d_154.html

Prometheus, The Use of Probabilistic Climate Data to Future-Proof Design Decisions in the Building Sector, University of Exeter, Downloads,

(http://centres.exeter.ac.uk/cee/prometheus/downloads.html, accessed October 2010.

Recommendations for the storage and exhibition of archival documents, BS 5454:2000.

UK Climate Projections (UKCP09), UK Climate Impacts Programme, http://www.ukcip.org.uk/index.php. 


\section{Figure Captions}

Figure 1: Q1 repository building at The National Archives, Kew, UK. The repositories are located in floors 2, 3 and 4. The insert shows the typical interior with record boxes holding archives held in open shelves.

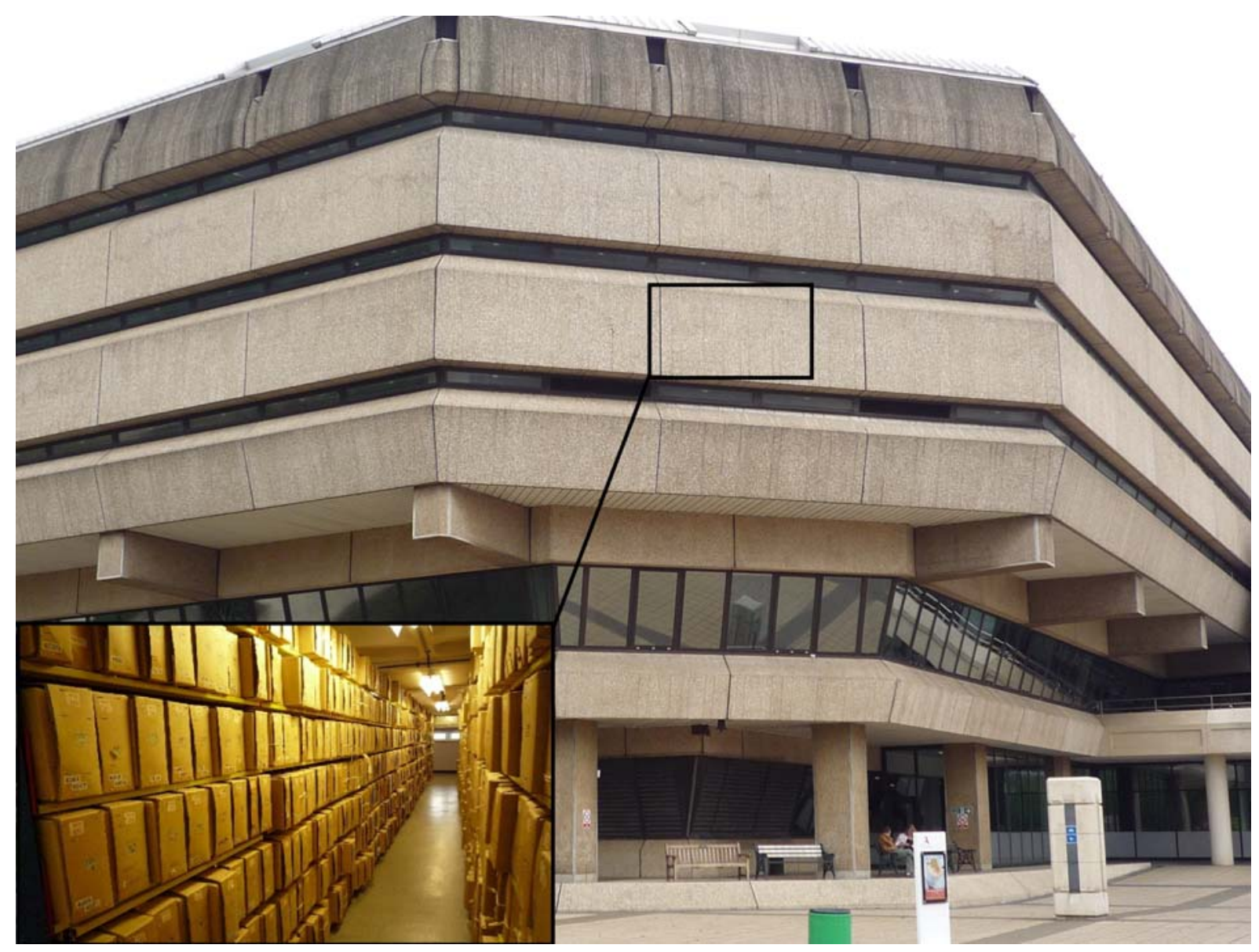


Figure 2: The process followed in the development of the energy and environmental simulation model.

\section{Model Construction} based on

Physical dimension Material property Internal load (people, lighting) HVAC operation

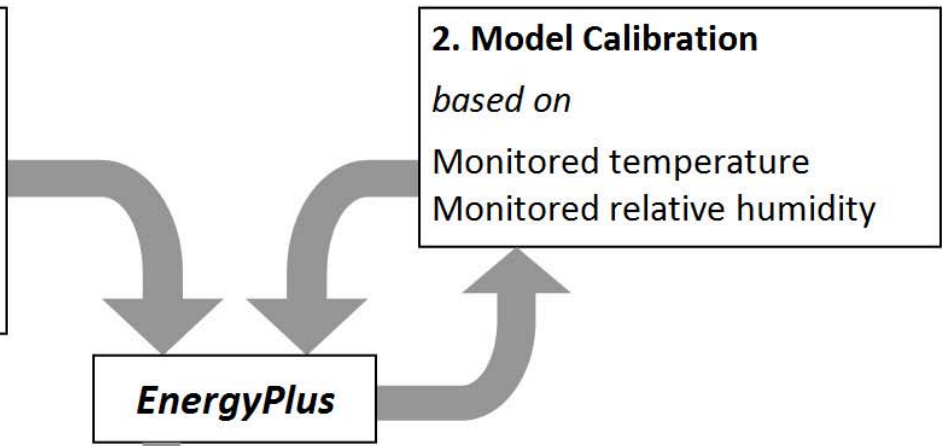

3. Modelling Baseline to establish reference

Temperature Relative humidity Energy load

\section{Modelling Scenarios} for

Changes in roof insulation Changes in archive volume Changes in HVAC operation Changes in external conditions

Figure 3: Monitored sorption isotherm of a typical record box with its paper content measured at $18^{\circ} \mathrm{C}$.

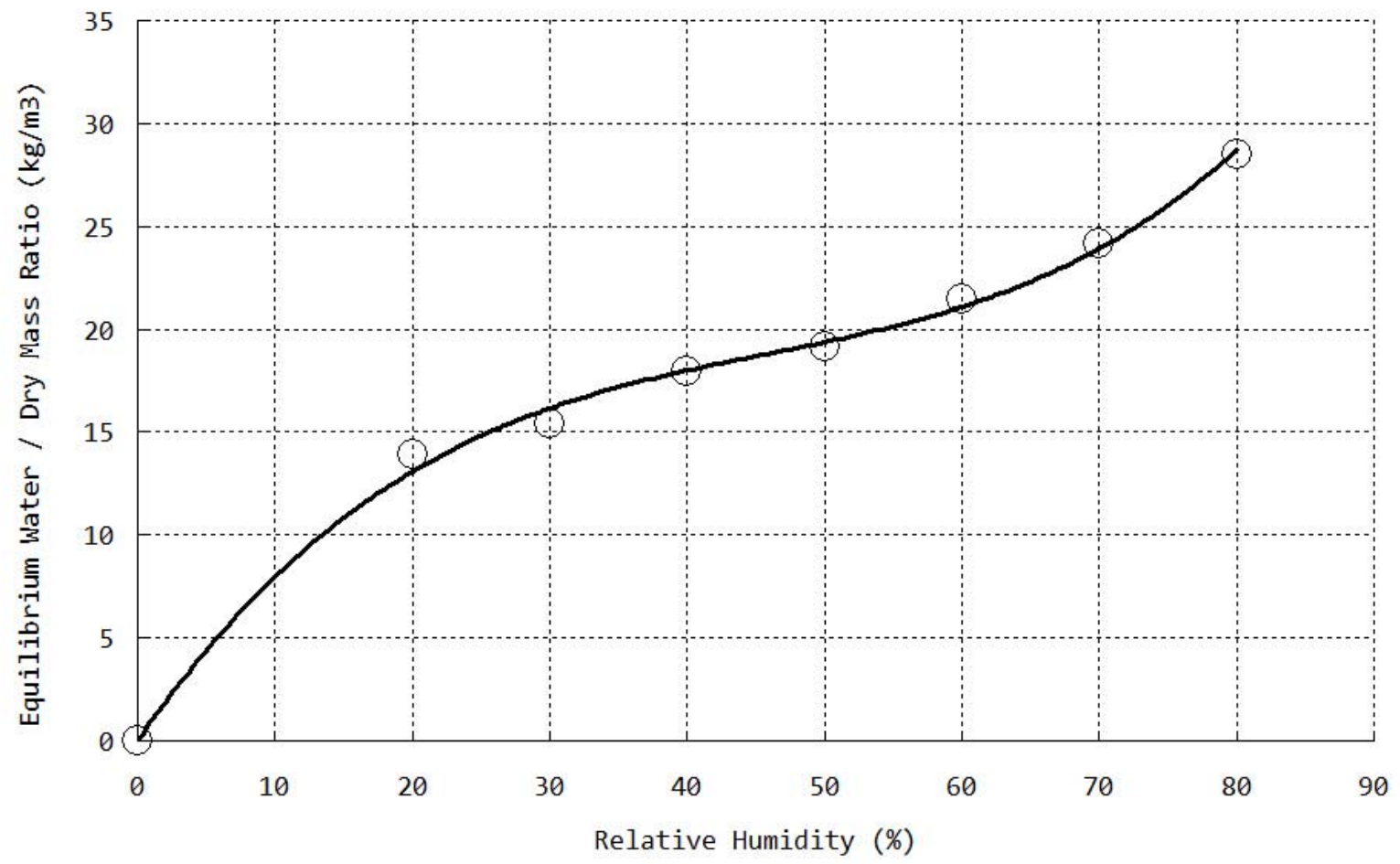


Figure 4. Annual London temperature distribution for the present (2009), 2050 and 2080 under high emissions scenario based on UKCP09 projections.

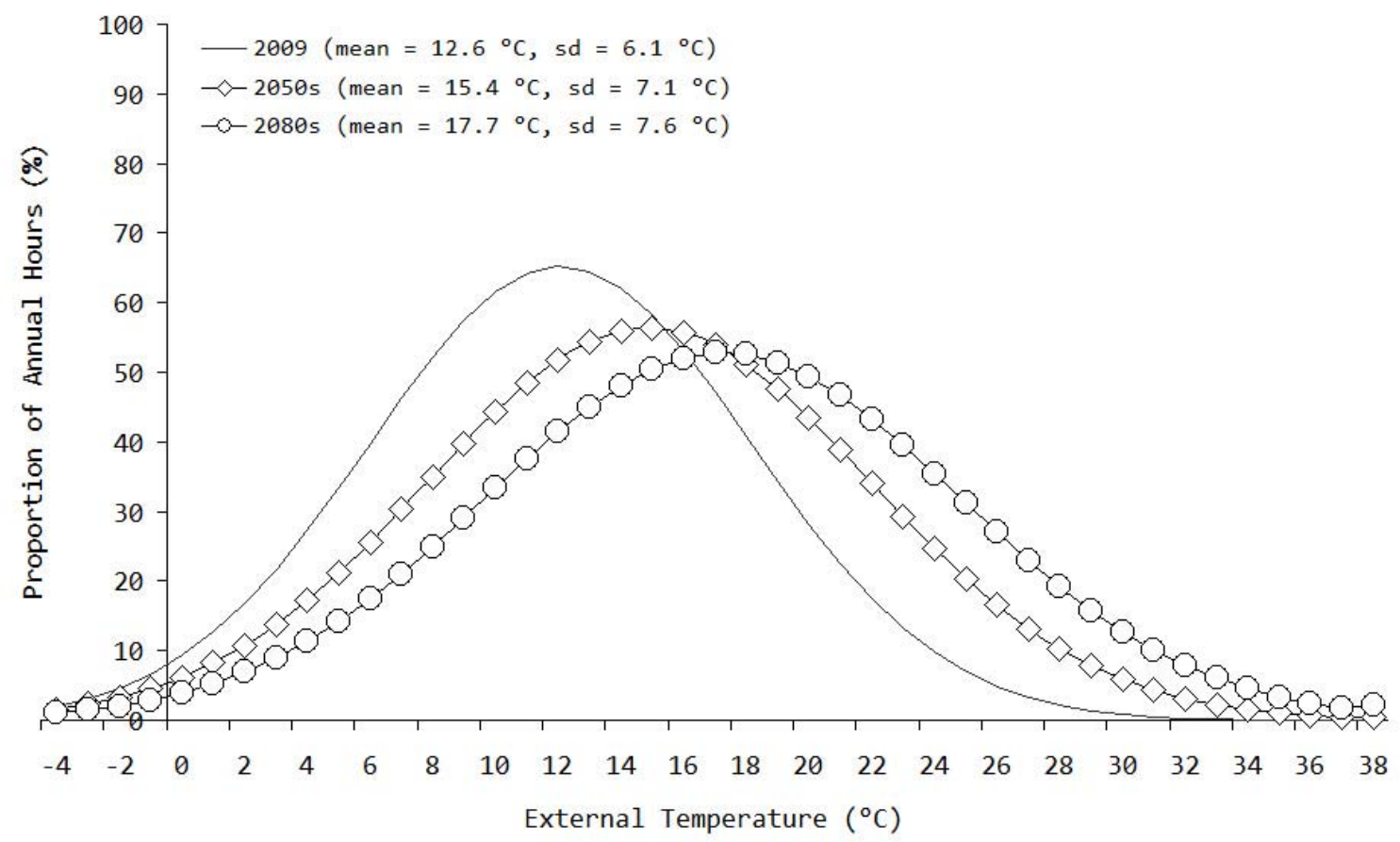

Figure 5. Mean monthly isoperm of the three repository floors under the baseline scenario.

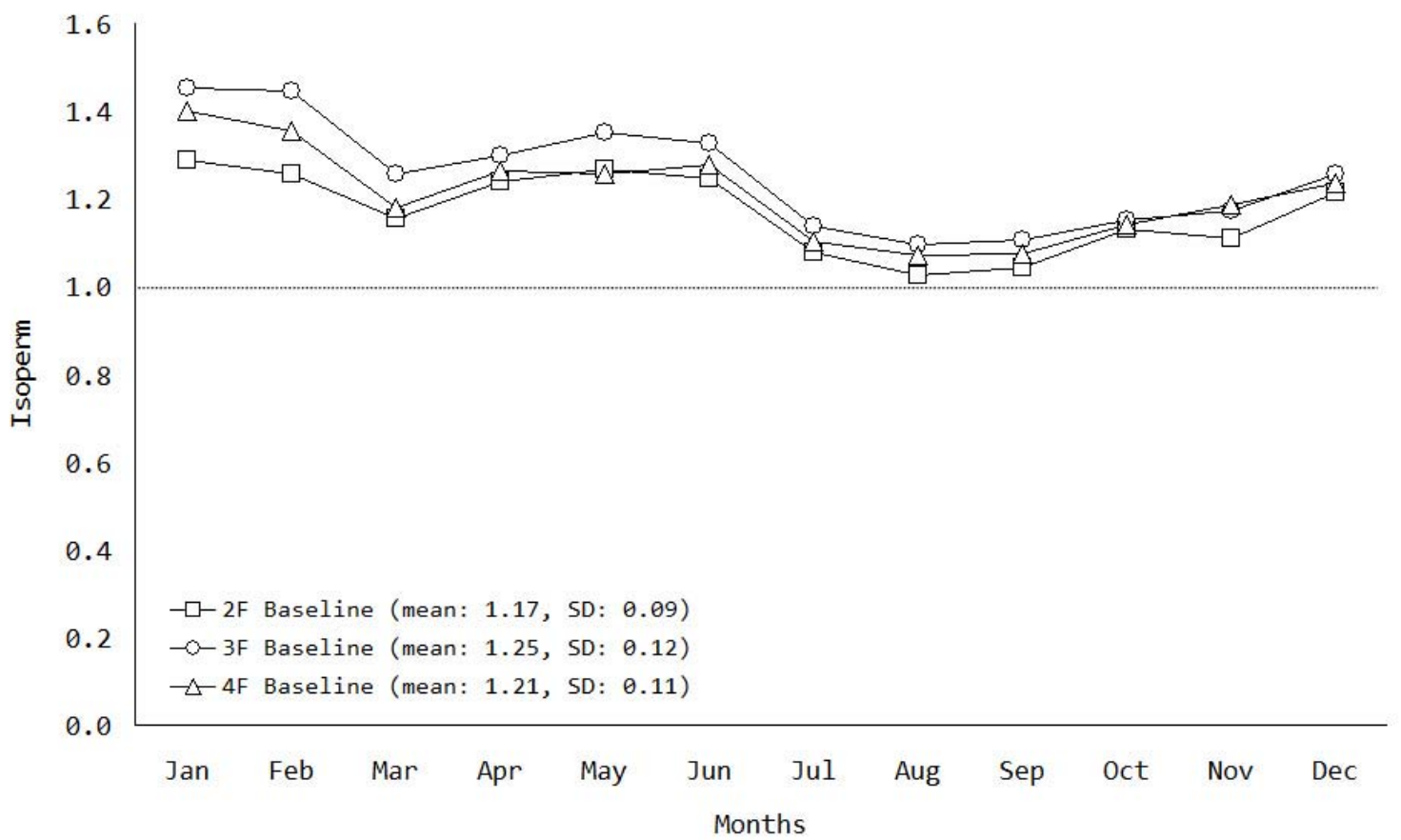


Figure 6. $4^{\text {th }}$ floor repository energy loads compared between different roof insulation thicknesses under the present and future $(2050,2080)$ climate scenarios.

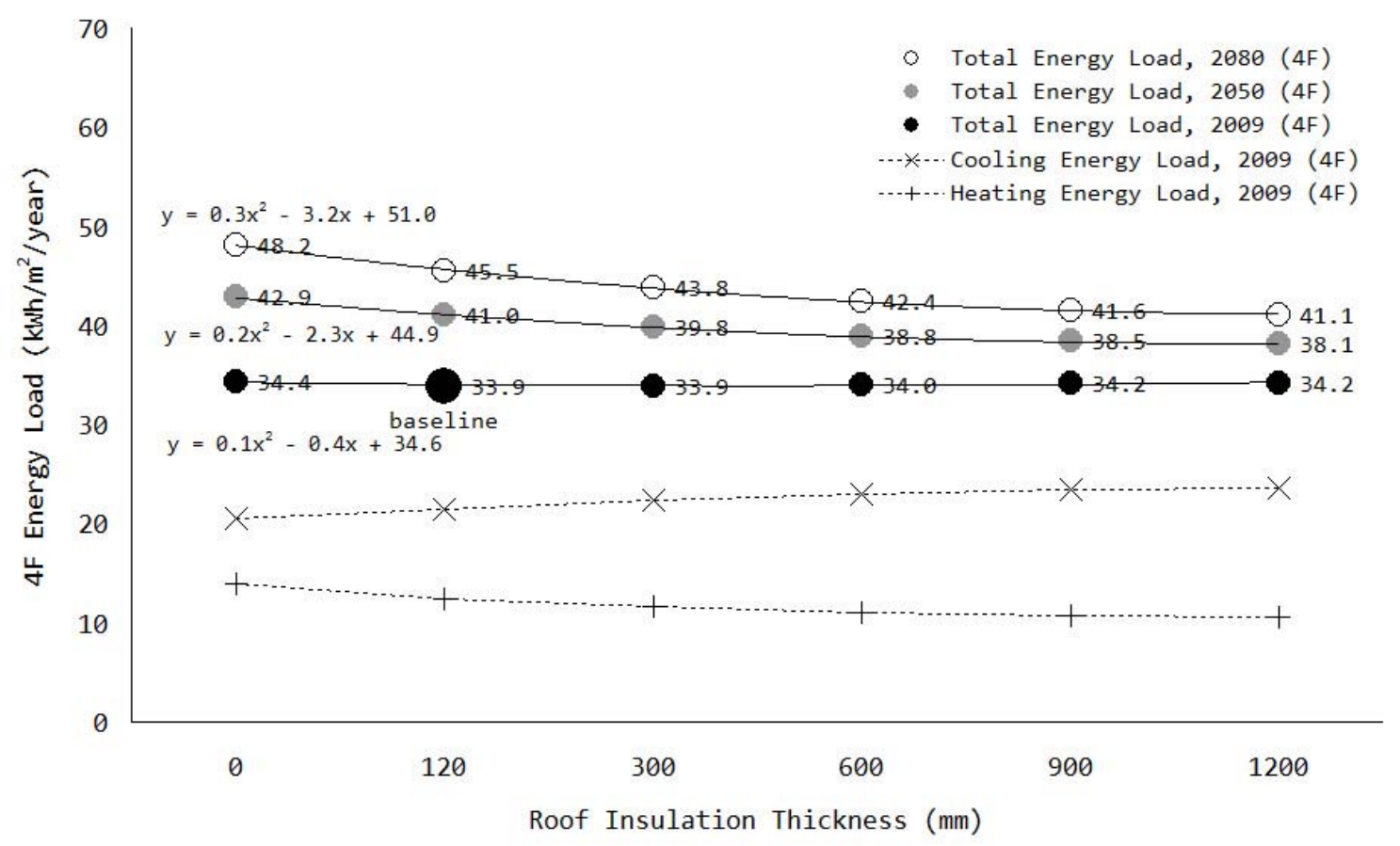

Figure 7. Comparsion of $3^{\text {rd }}$ floor monitored repository relative humidity performance under different archive volumes. The mean and standard deviations represent annual (2009) values but the figure shows humidity performance for the months of June and July only for clarity.

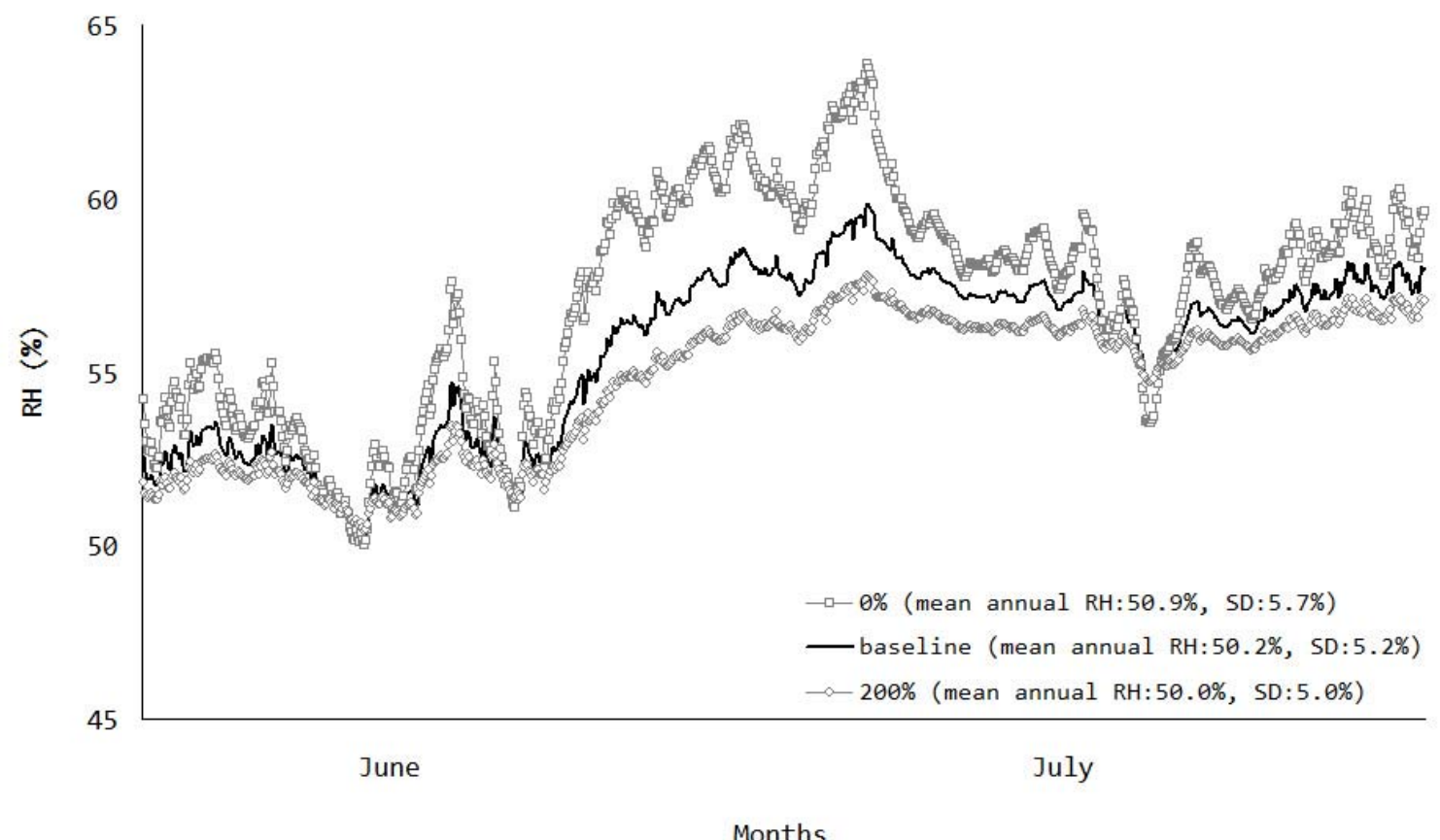


Figure 8. Energy loads compared between different archive volumes under the present and future $(2050,2080)$ climate scenarios.

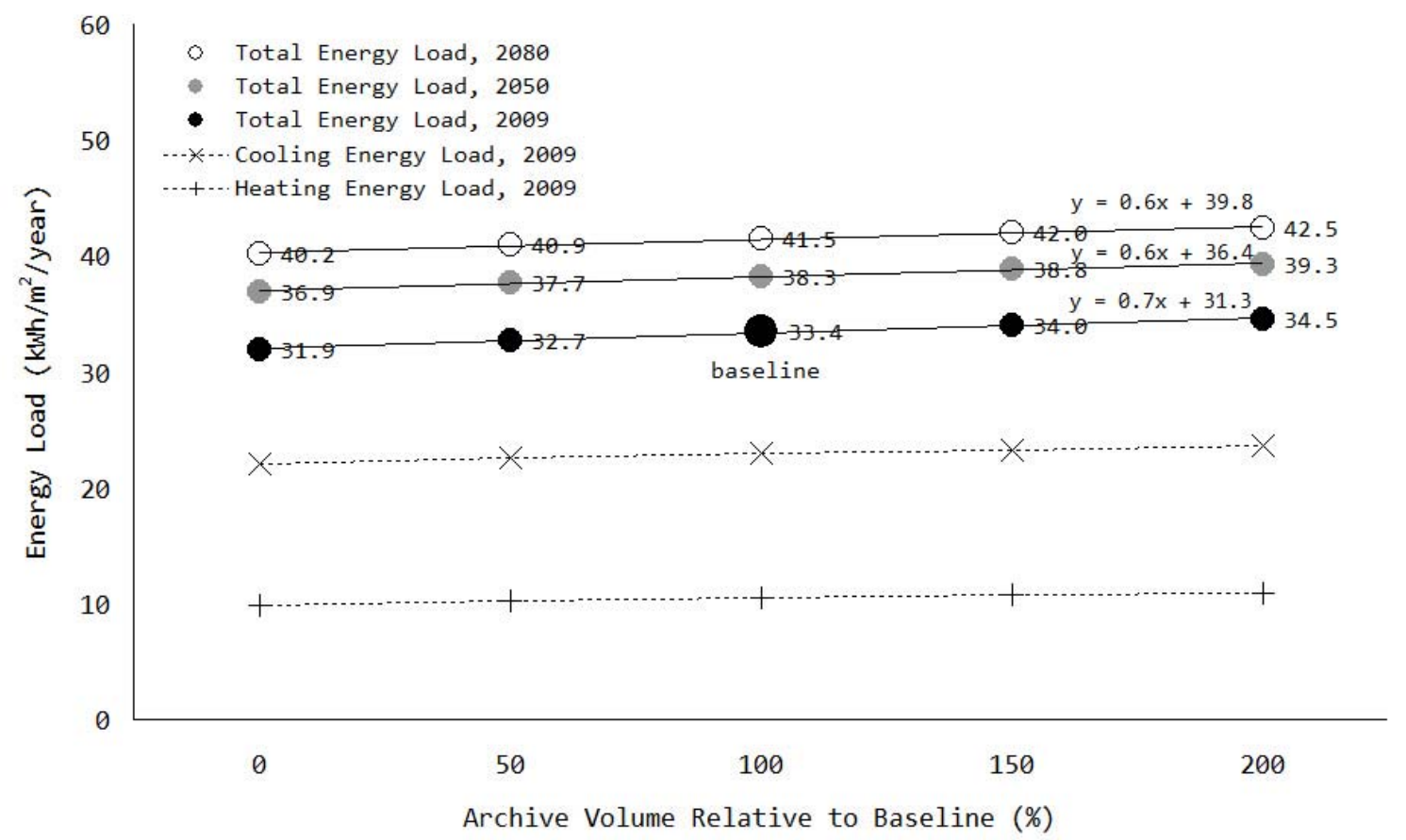

Figure 9. Mean monthly isoperm of the three repository floors compared between the baseline and the weekend HVAC power down scenarios.

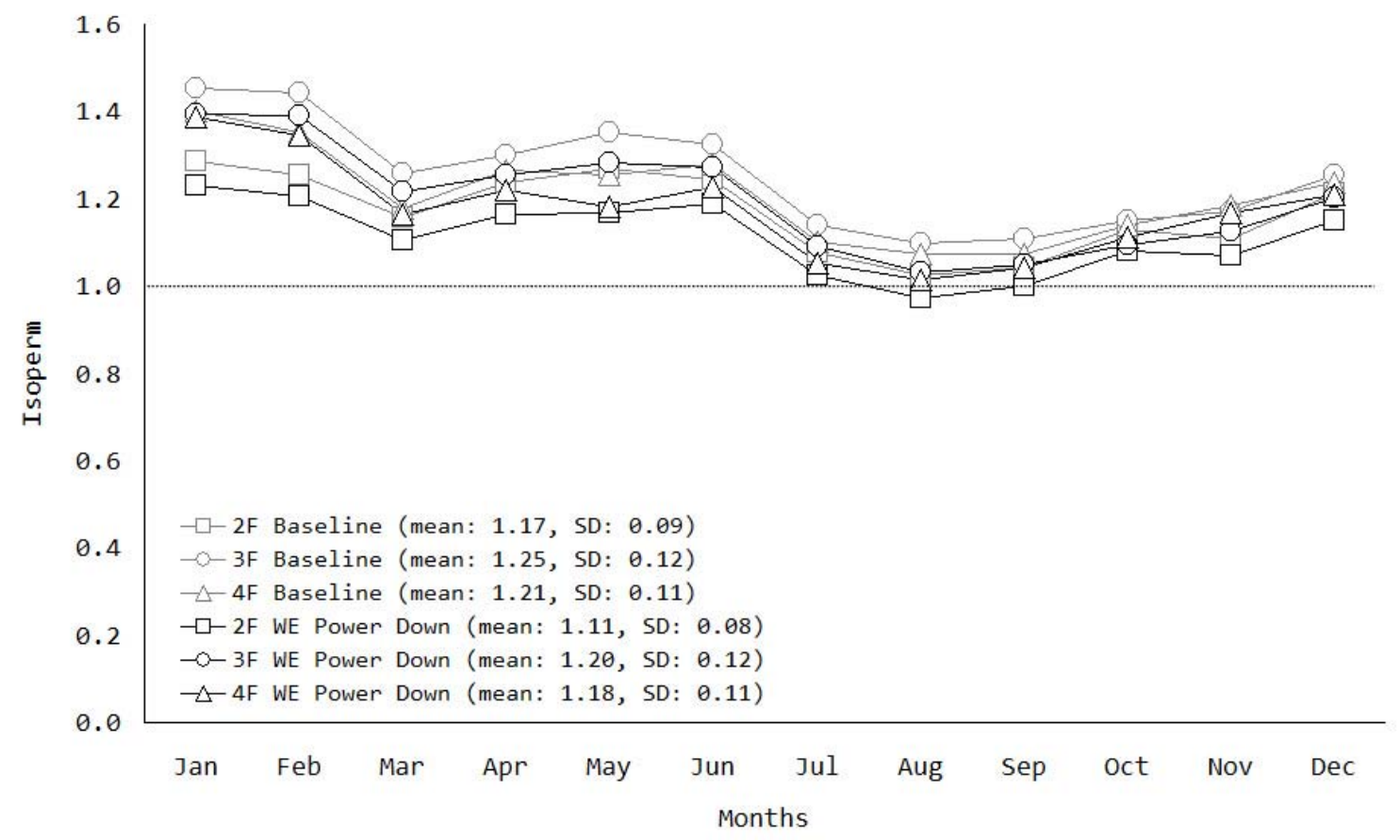


Figure 10. Energy loads compared between the baseline and the weekend HVAC power down scenarios under the present and future $(2050,2080)$ climate scenarios.

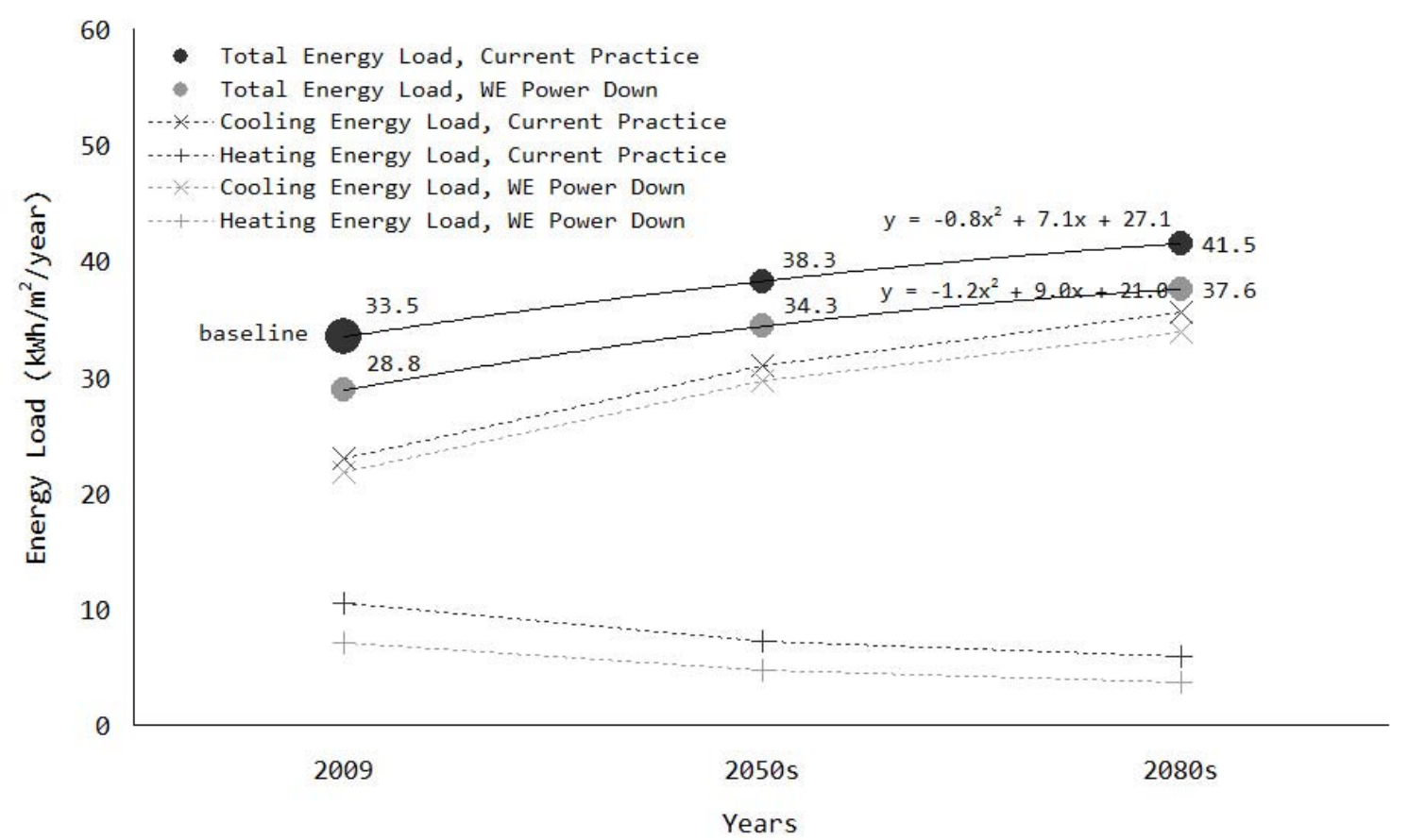

Figure 11. Mean monthly isoperm of the three repository floors compared between the baseline and the night time HVAC power down scenarios.

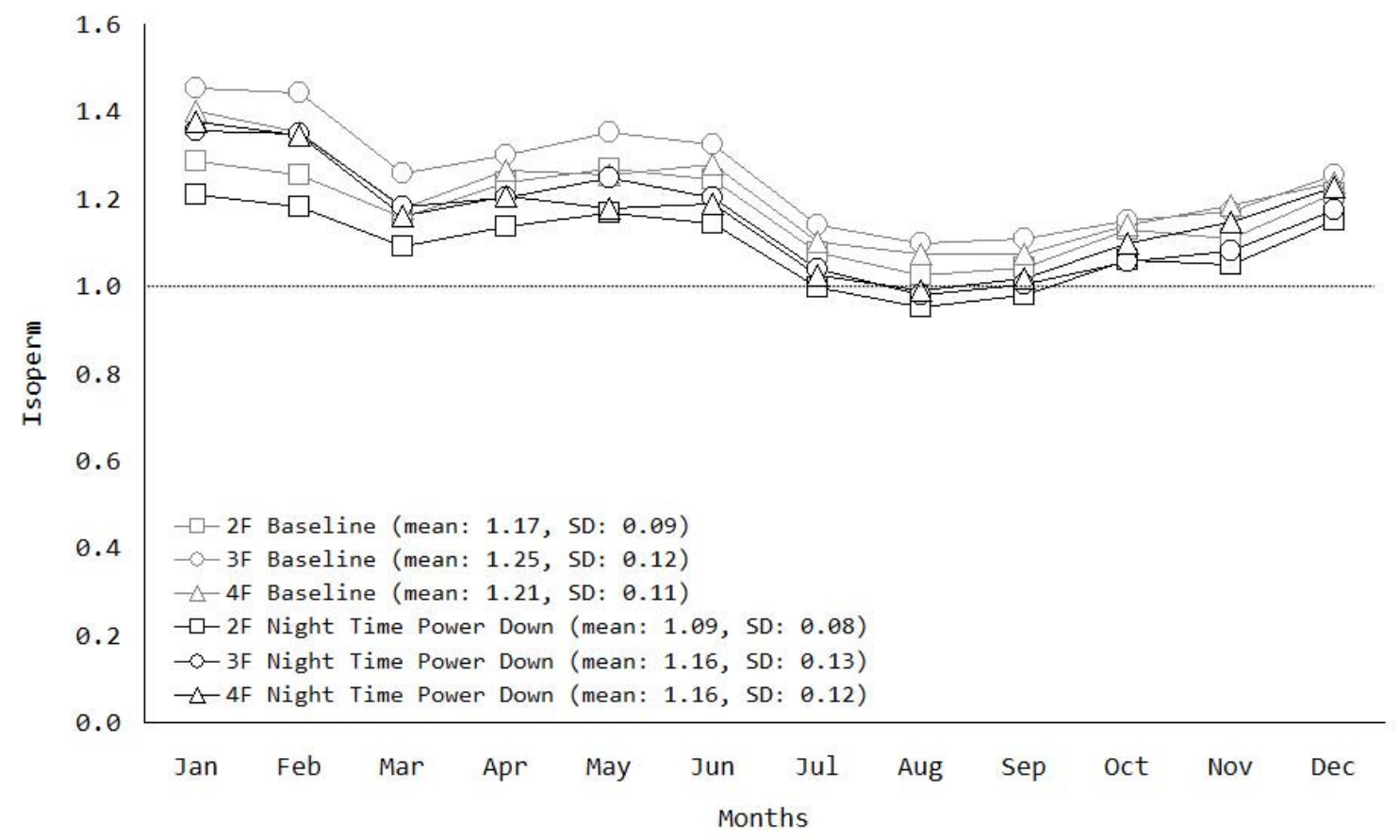


Figure 12. Energy loads compared between the baseline and the night time HVAC power down scenarios under the present and future $(2050,2080)$ climate scenarios.

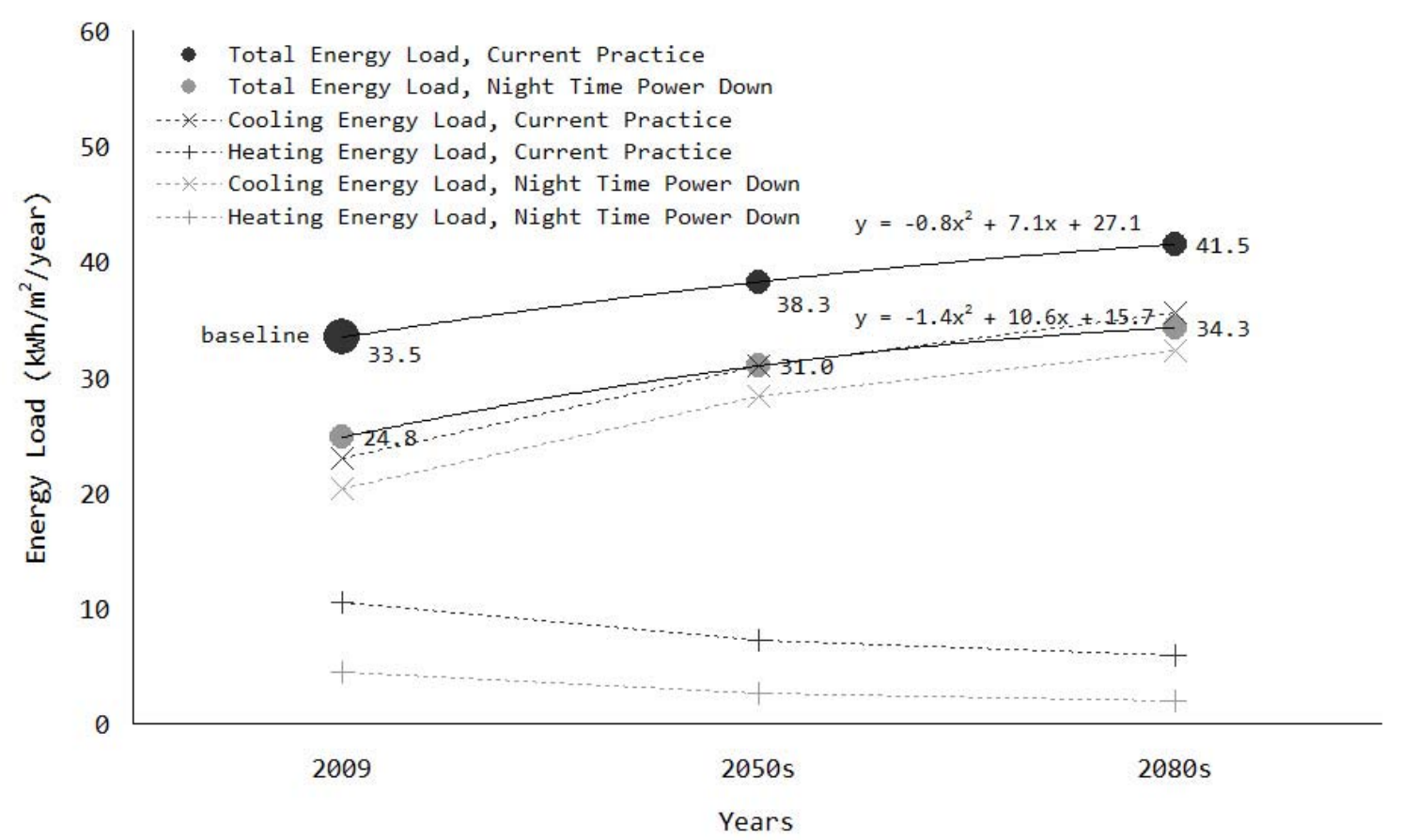

Figure 13. Mean monthly isoperm of the three repository floors compared between the baseline and the seasonally adjusted HVAC set point scenarios.

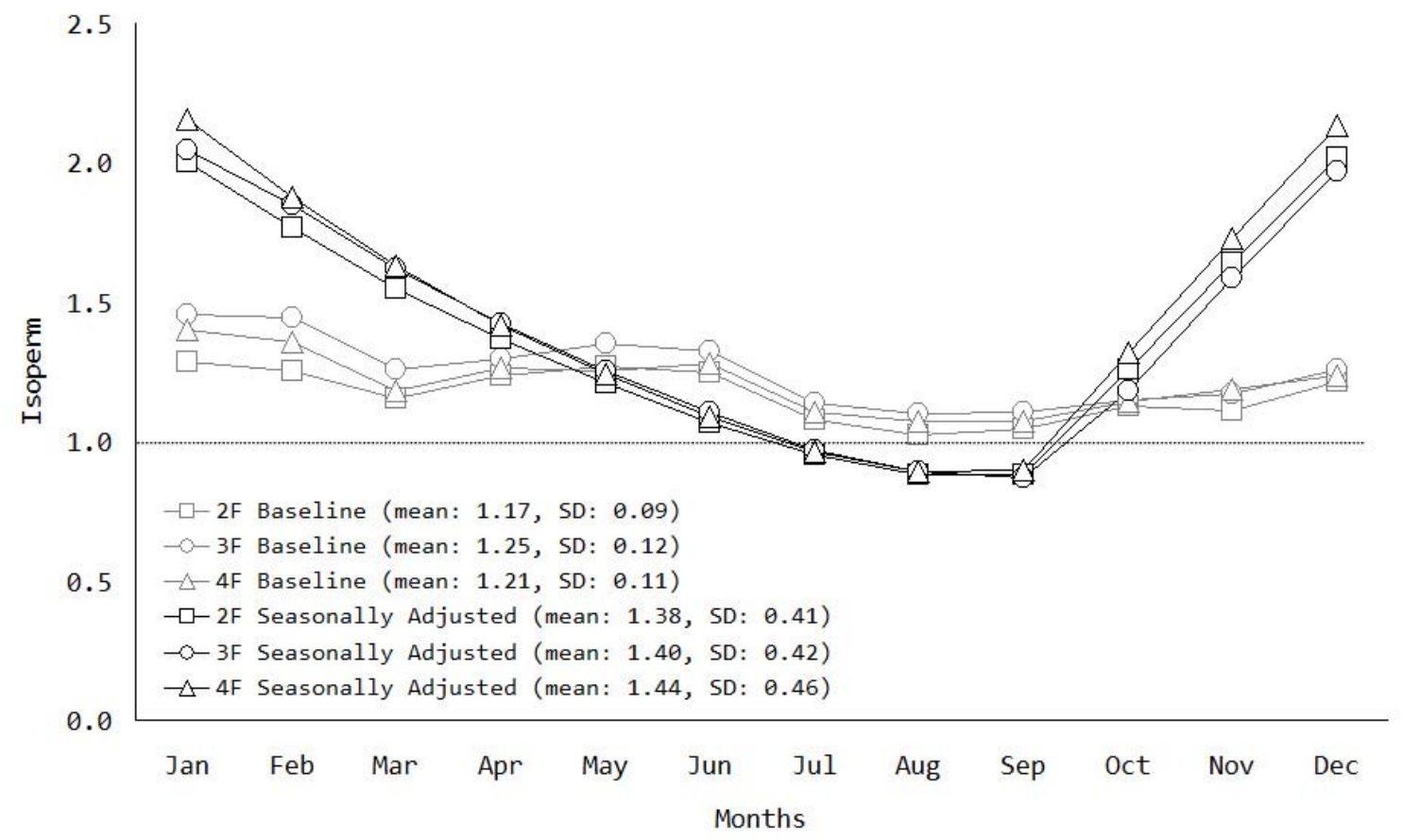


Figure 14. Energy loads compared between the baseline and the seasonally adjusted HVAC set point scenarios under the present and future $(2050,2080)$ climate scenarios.

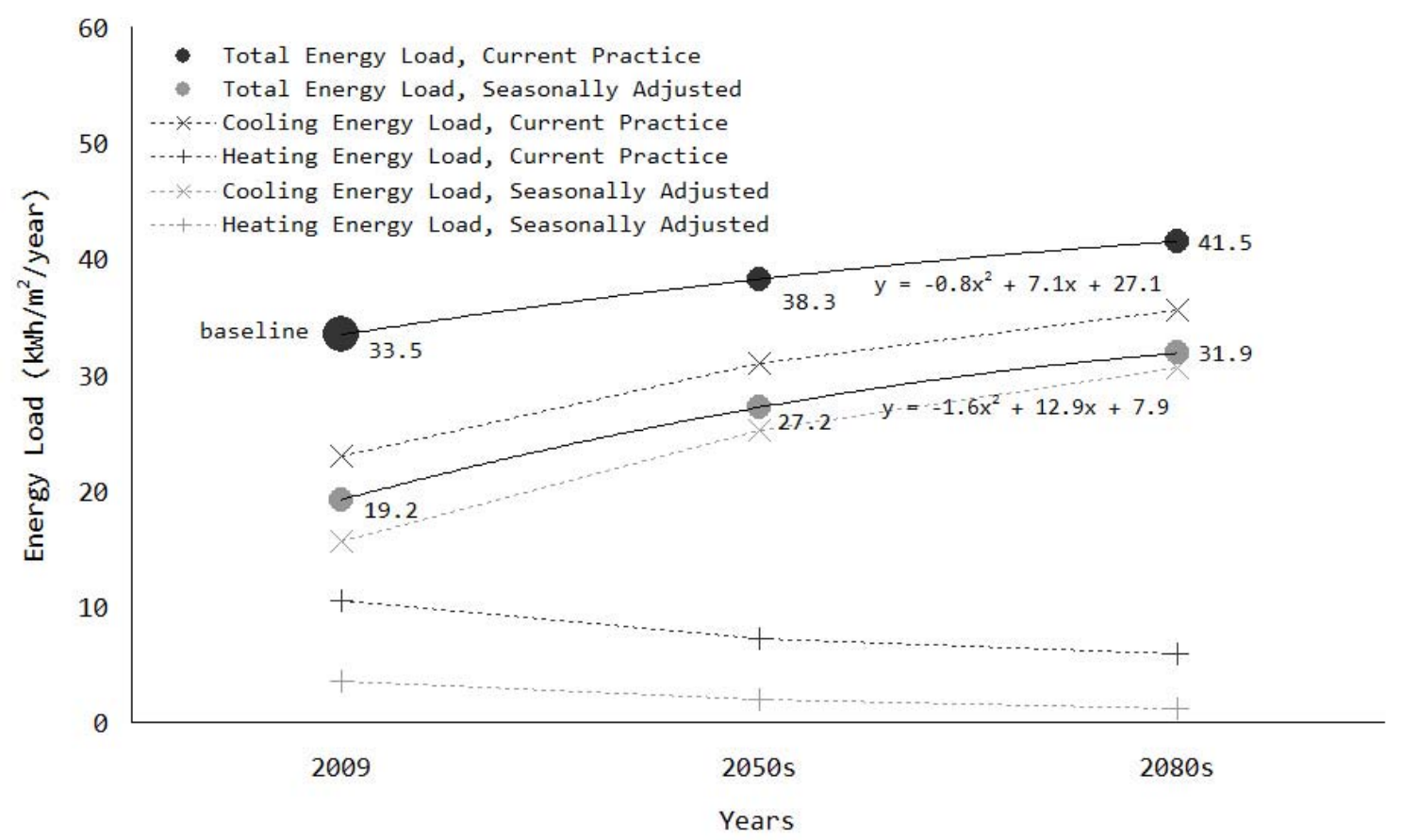




\section{Table}

Table 1: Comparison of baseline heating and cooling energy loads under the present (2009) and future climate scenarios. Values in parenthesis represent percent increase in comparison to 2009.

\begin{tabular}{|c|c|c|c|}
\hline \multirow{2}{*}{} & \multicolumn{3}{|c|}{ Annual Energy Loads (kWh/m ${ }^{2}$} \\
\cline { 2 - 4 } & 2009 & 2050 & 2080 \\
\hline Heating & 10.5 & $7.3(-30.5 \%)$ & $5.9(-43.8 \%)$ \\
Cooling & 22.9 & $31.0(+35.4 \%)$ & $35.6(+55.5 \%)$ \\
\hline Heating + Cooling & 33.4 & $38.3(+14.7 \%)$ & $41.5(+24.3 \%)$ \\
\hline
\end{tabular}

